\title{
La cultura de la supervivencia: carencias y excesos hídricos en la Huerta de Alicante (ss. XVI-XVIII)
}

\author{
Armando Alberola Romá \\ Grupo de Investigación en Historia y Clima. Universidad de Alicante \\ armando.alberola@ua.es
}

\begin{abstract}
Resumen. La Huerta de Alicante fue, durante la Edad Moderna, uno de los secanos regados más interesantes del Levante peninsular. El secular déficit hídrico dio lugar a un sistema de riego basado en un estricto cómputo horario y a la construcción de presas que retuvieran y desviaran el agua generada por las precipitaciones extraordinarias otoñales. El modélico pantano de Tibi (1579-1594) levantado en el curso del río Montnegre es un excelente ejemplo de la necesidad acuciante de almacenar agua para poder regar los campos en los períodos clave del ciclo agrícola pero, también, del deseo de evitar que los caudales -tan extraordinarios como necesarios- producto de las precipitaciones otoñales se perdieran en el mar. El embalse de Tibi y los azudes de Mutxamel, Sant Joan y El Campello, localizados aguas abajo de la misma, compusieron un singular sistema hidráulico sistemáticamente sometido a los vaivenes de la meteorología. Las pertinaces sequías padecidas durante la Edad Moderna, junto con los excesos hidrometeorológicos, contribuyeron a crear una peculiar "cultura del agua" en la que técnica, control institucional y religiosidad popular se dieron la mano y contribuyeron a componer un paisaje de regadío deficitario de enorme interés que ha estado vigente hasta las décadas postreras del siglo pasado.
\end{abstract}

Palabras clave. Déficit hídrico, sequía, tormentas, inundaciones, obras hidráulicas, rogativas, pantano de Tibi, azudes, río Montnegre (Alicante).

\begin{abstract}
Culture of survival: water shortage and excess in the Huerta of Alicante (XVI-XVIII centuries). The Huerta of Alicante was along the Modern Age, one of the most interesting irrigated dryland in the Eastern Iberian Peninsula. The secular water deficit led to an irrigation system based on a strict schedule computation and the construction of dams to hold and divert the water generated by the extraordinary autumn rainfall. The modelic Tibi's reservoir built (1579-1594) in the Montnegre river is an excellent example of the pressing need to store water to irrigate the fields at key periods of the agricultural cycle, but also an expression of the desire to avoid the flows produced by the intense storms of autumn were lost at the sea. Tibi's reservoir and dams of Mutxamel, Sant Joan and El Campello -raised downstream-, composed a unique hydraulic system systematically subjected to the vagaries of the weather. The droughts and hydrometeorological excesses experienced during the Modern Age contributed to create a unique "water culture" in which technics, institutional control and popular religiosity shook hands and helped to the configuration of a poor irrigated landscape of enormous interest, wich has been in force until by the last decades of the last century.
\end{abstract}

Keywords. Water shortage, drought, storms, floods, water works, rogations, Tibi reservoir, dams, Montnegre river (Alicante).

«El agua es nuestro Dios, nuestro ídolo, terrible en sus enfados, amante dadivoso cuando sonríe, salta y brilla por nuestro campo y todo lo penetra. Hijos de la tierra del sol, el sol nos agosta y el agua nos salva».

(Rafael Altamira, La fiesta del agua, 1895).

\section{Introducción}

La vieja huerta de Alicante, llano litoral que se extendía al NE de la ciudad, constituyó en siglos pasados uno de los ejemplos más significativos de regadío deficitario o, si se prefiere, secano mejorado existente en tierras valencianas. En producción hasta finales de los años sesenta del siglo XX, resulta irreconocible en la actualidad, tras haber sufrido el embate de un enloquecido y feroz proceso urbanizador que apenas ha dejado indemne alguna de sus señas de identidad pese a los intentos de recuperación desarrollados por colectivos ciudadanos (López Gómez, 1951). 
En la cartografía histórica, la huerta alicantina aparece resaltada a modo de mancha o lunar verde, tal como la denominaron los cronistas locales y regnícolas de los siglos modernos o los viajeros que transitaron por estas tierras. Ese color contrasta abiertamente con los grises y ocres de la amplia superficie que la circunda y que claramente evocan el secano. Con unos suelos razonablemente propicios para el cultivo de diferentes productos, el clima mediterráneo, que en este ámbito adquiere ya características subáridas, ha sido un tradicional condicionante de los rendimientos agrícolas. A salvo de temperaturas extremas invernales y de los efectos de los vientos del norte y del oeste gracias al cerco montañoso que la envuelve desde las estribaciones de la cumbre del Maigmó hasta el barranco de Aigües de Busot, la Huerta de Alicante llegó a tener en cultivo entre los siglos XVI y XVIII una superficie cercana a las 30.000 tahúllas (unas 3.600 hectáreas) dedicada a diferentes especies de suelo y vuelo. El déficit en la producción triguera -habitual por otra parte en todo el viejo reino valenciano- quedaba compensado por los notables rendimientos que proporcionaba la vid que, transformada en vino, rendía excelentes beneficios económicos gracias a su exportación a través del puerto (Giménez López, 1981; Alberola, 1984; Alberola, 1994).
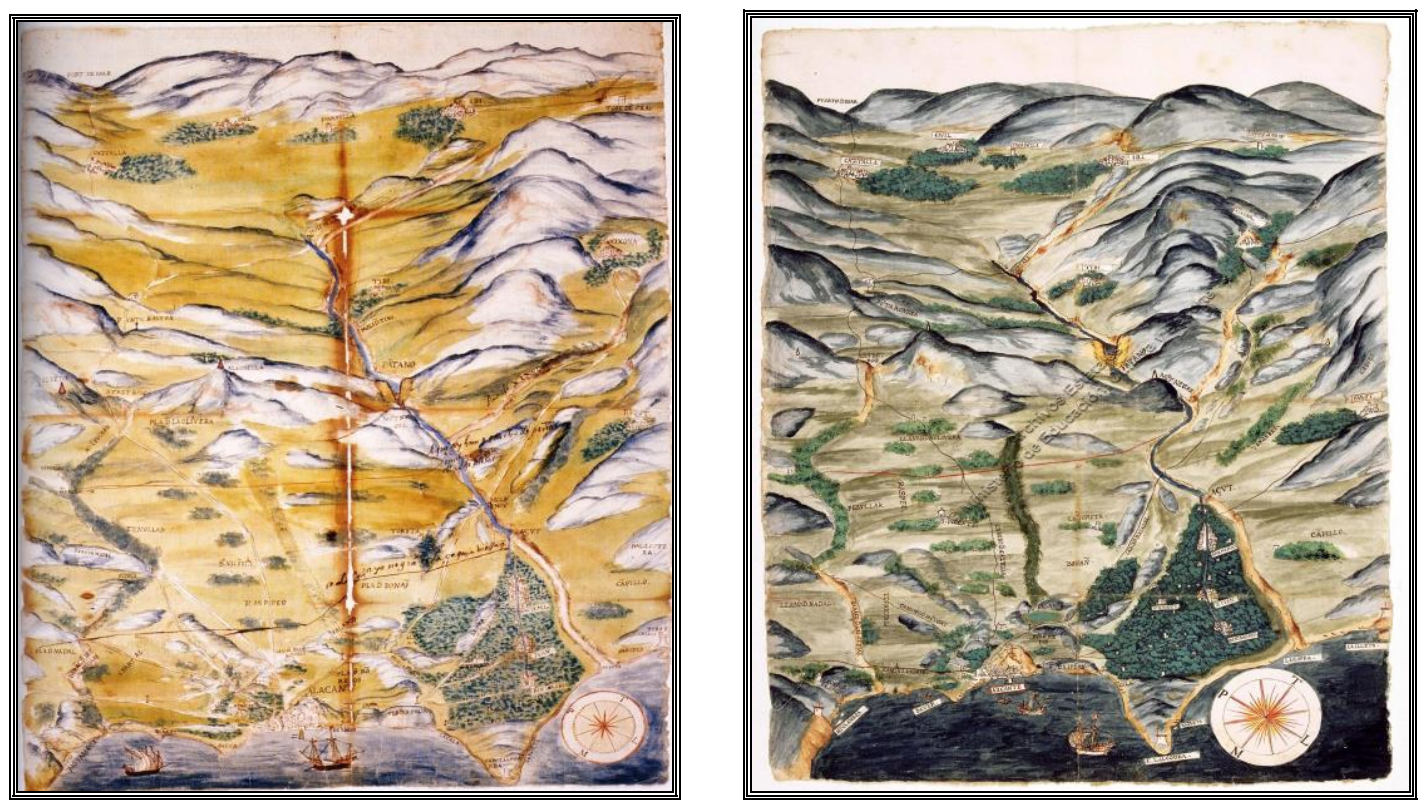

Fig 1. La Huerta de Alicante en las postrimerías del siglo XVI (Archivo de la Corona de Aragón).

Sin embargo, la huerta alicantina padecía el grave inconveniente de no disponer de suficiente agua para su riego, sobre todo durante el verano, período clave del calendario agrícola. $\mathrm{Y}$ es que el clima mediterráneo, suave y bonancible, encubre serios problemas: escasez de precipitaciones, elevada irregularidad interanual e intensa evapotranspiración potencial (Gil Olcina, 1993). Las lluvias, escasas pero torrenciales cuando las hay, descargan fundamentalmente en primavera y otoño, no así en el estío, observándose un doble máximo otoñal en septiembre/octubre y octubre/noviembre al que sucede un invierno, por lo general seco, seguido de un máximo de precipitaciones en el mes de abril. Los cronistas de la época, tan proclives a ensalzar las bondades del terruño, incurren en notorias contradicciones. Es el caso del deán alicantino Vicente Bendicho quien, tras destacar en su Crónica lo abundante y variado de la producción agrícola huertana, confesaba asimismo que «siempre ba sido esta tierra estéril de aguas» a la vez que indicaba que la razón que motivó la construcción del famoso pantano de Tibi fue «la necesidad y falta de agua que havía en el término de aquesta Ciudad para riego de sus campos y vega» (Bendicho, 1640). El jesuita expulso Antonio 
Conca, valenciano él, empleaba similares argumentos un siglo y medio más tarde en su poco conocida Descrizione odeporica della Spagna, donde se refería la Huerta alicantina como «pianura estremadamente fertile» en la que se localizaban cuatro poblaciones, «eleganti casini di campagna e molti giardini» para añadir a continuación que este «deliz̧ioso tratto di paese si conesceva anticamente col nome di V all seca per la mancanza che v'era d'acqua» (Conca, 1797).

En estas circunstancias no debe extrañar que el agua -escasa, de disponibilidad irregular y elevado precio- fuera prontamente monopolizada por unos pocos desde los primeros repartos efectuados tras la Reconquista y, con no menor rapidez, separada de la tierra a la que estaba unida. Por ello, tampoco cabe sorprenderse de que, desde tiempo inmemorial, el agua fuera considerada por los campesinos del sur valenciano como el bien por excelencia, más incluso que el disfrute de la propiedad de la tierra. Y en ello influyó mucho, además del clima mediterráneo, la hidrografía valenciana. Por lo que hace a esta última, el territorio de la antigua Gobernación foral d'enllá Sexona carecía -carece- de ríos de curso largo y caudal abundante exceptuando el Segura; y sobre éste gravitaba el inconveniente de que la vega murciana consumía buena parte de sus caudales. De ahí que, como ahora, el regadío estuviera condenado en tierras alicantinas a sobrevivir con las aguas que proporcionaban corrientes modestas y profusamente explotadas en sus tramos iniciales y medios -como los ríos Vinalopó o Montnegre, para los regadíos de Elche y Alicante respectivamente-, y las esporádicas -y habitualmente extraordinarias en cantidad e intensidad horaria- procedentes de ramblas, ríos-rambla y torrentes que entraban en acción tras las precipitaciones otoñales o primaverales. El resto del año predominaba la precariedad hídrica y con ella largos períodos de sequía; circunstancia que obligó al común de ciudades y villas a poner en marcha diferentes mecanismos para contrarrestar sus efectos.

Todas estas circunstancias han contribuido a configurar una cultura hídrica estrechamente vinculada a la carencia, al ahorro, al padecimiento por la sequía y a la necesidad de idear las infraestructuras adecuadas para no perder los escasos caudales circulantes y los esporádicos $\mathrm{y}$ violentos procedentes de precipitaciones extraordinarias. $\mathrm{Y}$ en esta cultura, no exenta de fatalismo, la técnica y la religiosidad popular se dieron la mano siglos atrás y, en buena medida, siguen manteniendo esta relación para hacer frente de consuno al grave déficit hídrico.

\section{Recursos hídricos y organización del riego en la Huerta de Alicante (siglos XVI- XVIII)}

La sequía constituyó durante la Edad Moderna uno de los principales problemas para los labradores; si no el mayor. No hay que olvidar que en el período preindustrial la relación entre clima y agricultura era muy estrecha y obligaba a aquéllos a estar muy pendientes del cielo (Le Roy Ladurie, 1991). Los alicantinos dedicaron secularmente sus afanes a combatir sus efectos, tal y como destacaba, con admiración, el botánico ilustrado Antonio José Cavanilles cuando recorrió su huerta entre los días 20 y 22 de julio del año 1792, tras arribar a Alicante la tarde del 19 y partir hacia Elx en la mañana del 23 (Mateu, 1995, I, 29):

«No había allí aguas para el riego, y se condujeron de quatro leguas de distancia: presentaba el suelo con freqüencia obstáculos al cultivo y se vencieron todos. Si no quedaran rastros del estado antiguo de la huerta [de Alicante], si no existieran las soberbias obras del pantano, azudes y canales, no podrían apreciarse los esfuerzos, los gastos y la dichosa transformación del suelo. Han trabajado los Alicantinos con tesón y conocimiento, y hallado recompensa en los campos, que producen deliciosas frutas, rico aceyte, excelentes vinos, [...]. A la calidad y cantidad de frutos se debe añadir la seguridad casi absoluta» (Cavanilles, 1795-1797, II, 225). 
Rafael Altamira, un siglo después, también resumía a la perfección el sentido, la utilidad y, sobre todo, la necesidad de una obra como el pantano de Tibi, al que consideraba como un auténtico símbolo:

«Si no fuera por el Pantano [...], un pantano hermoso que tenemos allá arriba en la montaña y que recoge las lluvias para los días de escasez, la miseria sería permanente aquí. Gracias a él, se puede regar cada mes, y a veces, en años lluviosos, más a menudo; y siempre es para nosotros una emoción el riego. Pero cuando falta también el Pantano, o escasea su contenido jadiós tierra!» (Altamira, 1895)

La lucha contra la sequía y los esfuerzos desplegados para acrecentar los recursos hídricos han sido hitos muy señalados en la historia agraria valenciana que, no obstante disponer en general de suelos adecuados e inmejorables condiciones climáticas, carecía de lo fundamental: un riego permanente (Alberola, 2010b). Y así lo hacía notar en los primeros años del siglo XX, Manuel Lorenzo Pardo, padre del I Plan Nacional de Obras Hidráulicas, cuando afirmaba que «la zona verdaderamente apta para el cultivo de regadío es la mediterránea (...), donde se conservan las tradiciones más vivas, las instituciones de riego más firmes, las prácticas más sabias, la mayor y más generalizada experiencia» (Romero, 1995). La falta de agua explica la construcción, desde época remota, de presas y artefactos para detener, desviar, conducir y acopiar agua así como el diseño de las consiguientes redes de canalización y distribución sobre las que se articularon complejos sistemas de regadío que, en buena medida, han perdurado hasta nuestros días. El agua, escasa en el sureste peninsular, se constituyó con el paso del tiempo en el bien más preciado, llegando a significar durante la Edad Moderna una fuente de riqueza superior incluso a la propiedad de la tierra (Alberola, 1990).

Se trataba de controlar los flujos hídricos e impedir la pérdida del más mínimo caudal de agua. En aquellos lugares donde éste era inferior al $\mathrm{m}^{3} /$ segundo -como en la Huerta de Alicante- es obvio que resultaba fácilmente manejable, aunque exigía un reparto muy cuidadoso. En estos casos la división temporal constituía la solución más fácil y exacta, y el valor de la fila, fil o bilo -la unidad más frecuente- se fraccionaba normalmente en minutos y se acomodaba a las disponibilidades hídricas. Fue el caso de los regadíos deficitarios en los que, por otro lado y como ya se ha dicho, el agua fue adscrita a la tierra en las primeras donaciones o repartos, aunque con el paso del tiempo se produjo una progresiva separación de ambas propiedades ${ }^{1}$.

Ejemplos suficientemente ilustrativos de esta situación son el Campo de Elche y la Huerta de Alicante regados, respectivamente, por los caudales del Vinalopó y del Montnegre ${ }^{2}$. Por lo que respecta a este último interesa resaltar que en el complejo sistema de riegos que rigió en la huerta alicantina desde las primitivas ordenanzas medievales se contemplaban, al margen de los repartos ordinarios de los 336 fils o bilos de agua de hora y media de riego cada uno en que fue dividido el caudal del río Montnegre ${ }^{3}$, los correspondientes a 336 partidores o venturas -pequeñas presas de derivación- que entraban en acción cuando se producían precipitaciones tormentosas y comenzaba a circular el agua desenfrenada por acequias y brazales. Su cometido consistía en retener y dirigir estas ocasionales y violentas corrientes hacia la Huerta para aprovecharlas y evitar su pérdida en el mar (Vergara, 1739; Verdú,

\footnotetext{
${ }^{1}$ A este tipo de distribución de aguas que descansaba en unidades de medida de tiempo fijo, asociado a la venta del agua y en la que ésta podía ser enajenada separada de la tierra lo denominó Glick yemenita (Glick, 1988), mientras que López Gómez, prefirió llamarlo regadío alicantino (López Gómez, 1951).

${ }^{2}$ En documentos medievales el río Vinalopó es llamado Secabis o Wad-arrambla. El Montnegre, por su parte, es conocido en su curso alto como Verde o Cabanes y ya en su último tramo, aguas abajo del embalse de Tibi, recibe popularmente la denominación de Seco; Gil Olcina, 1968; López Gómez, 1951.

${ }^{3}$ Por riguroso turno se regaban 16 hilos por día, subdivididos en dos bloques de ocho, uno por la mañana y otro por la noche. La reunión de los 336 hilos era conocida con el nombre de martava o tanda y duraba 21 días
} 
1739; Alberola, 1994); porque estas trombas, otoñales y primaverales, son las que han roto de tanto en tanto, aunque con una asiduidad claramente perceptible a lo largo de la historia, la sequía habitual derivada de ese régimen pluviométrico tan característico del ámbito mediterráneo, en general, y valenciano en particular.

No es momento de entrar en mayores detalles pero sí de indicar que, a comienzos de la Edad Moderna, la situación en la Huerta alicantina distaba mucho de ser lo que había sido a poco de producirse la reconquista cristiana y los primeros repartos de tierras y agua para su riego. Procedente ésta de los caudales del río Montnegre o Seco, otorgados a los alicantinos en exclusividad por el rey Alfonso X de Castilla, su gestión provocó problemas desde el principio. En primer lugar porque excluía de su disfrute a los campesinos del curso alto y medio del río; en segundo, porque su parquedad e irregularidad provocó de inmediato la especulación por parte de los propietarios más poderosos. El incremento demográfico, la necesidad evidente de ampliar la superficie cultivable y las circunstancias climáticas aludidas influyeron para que se construyera el modélico embalse de Tibi entre los años 1579-1594. El objetivo era evidente: almacenar agua para poder proporcionar riego a las tierras de la Huerta en los momentos más delicados del ciclo agrícola y, además, evitar su pérdida en el mar cuando se producían las intensas precipitaciones otoñales.

Aguas abajo de la presa de Tibi se levantarían durante la época moderna en el cauce del río Montnegre-Seco los azudes de Mutxamel y de Sant Joan y, ya en el siglo XIX, el de El Campello. Junto con estas obras hidráulicas, el sistema de riegos diseñado en época musulmana y organizado a base de acequias, brazales e hijuelas perseguía proporcionar agua a los lugares más recónditos de la huerta. La escasez hídrica, pero sobre todo la decisión de hacer frente al problema sin regatear esfuerzos ni dinero -no olvidemos que la obra de Tibi la pagaron los propios vecinos-, dieron como resultado unas soluciones técnicas que, a día de hoy, se antojan excepcionales habida cuenta los medios de que se disponía en aquellos momentos (Alberola, 1994). Las peculiaridades del regadío en las áridas tierras del sureste peninsular, sobre todo por lo que se refiere a los sistemas de riego de determinadas huertas como la de Alicante, llamarían poderosamente la atención de ingenieros, geógrafos y expertos en cuestiones agrarias, tanto españoles como extranjeros, durante el siglo XIX. Es el caso, por ejemplo, del francés Maurice Aymard (1864), el inglés Clements Markham (1867) o de los españoles Joaquín Roca de Togores (1849) y Andrés Llauradó (1884), autores de espléndidos informes y tratados en los que incluyen un detallado diseño y explicación del sistema de riegos (Alberola, 1996).

Pero junto a la técnica, la religiosidad popular siguió un camino paralelo. En un doble sentido. Por un lado, demandando del altísimo la solución del problema mediante los rituales establecidos al efecto y, por otro, controlando las conciencias mediante la acción directa de los clérigos sobre sus feligreses a quienes trasladaban mediante encendidos sermones la responsabilidad de cualquier desastre -y la sequía lo era- tras acusarles de cometer tal cúmulo de hipotéticos pecados que habían conseguido acabar con la infinita paciencia y bondad divinas. El rezo de plegarias específicas, la celebración de rogativas bien fueran pro pluvia o pro serenitate- y de procesiones penitenciales portando reliquias $\mathrm{o}$ imágenes de vírgenes, santos y santas, constituían remedios considerados muy eficaces por una sociedad tan sacralizada como la de esta época a los que se podían añadir, si las circunstancias lo exigían, conjuros y exorcismos (Alberola, 2011). 

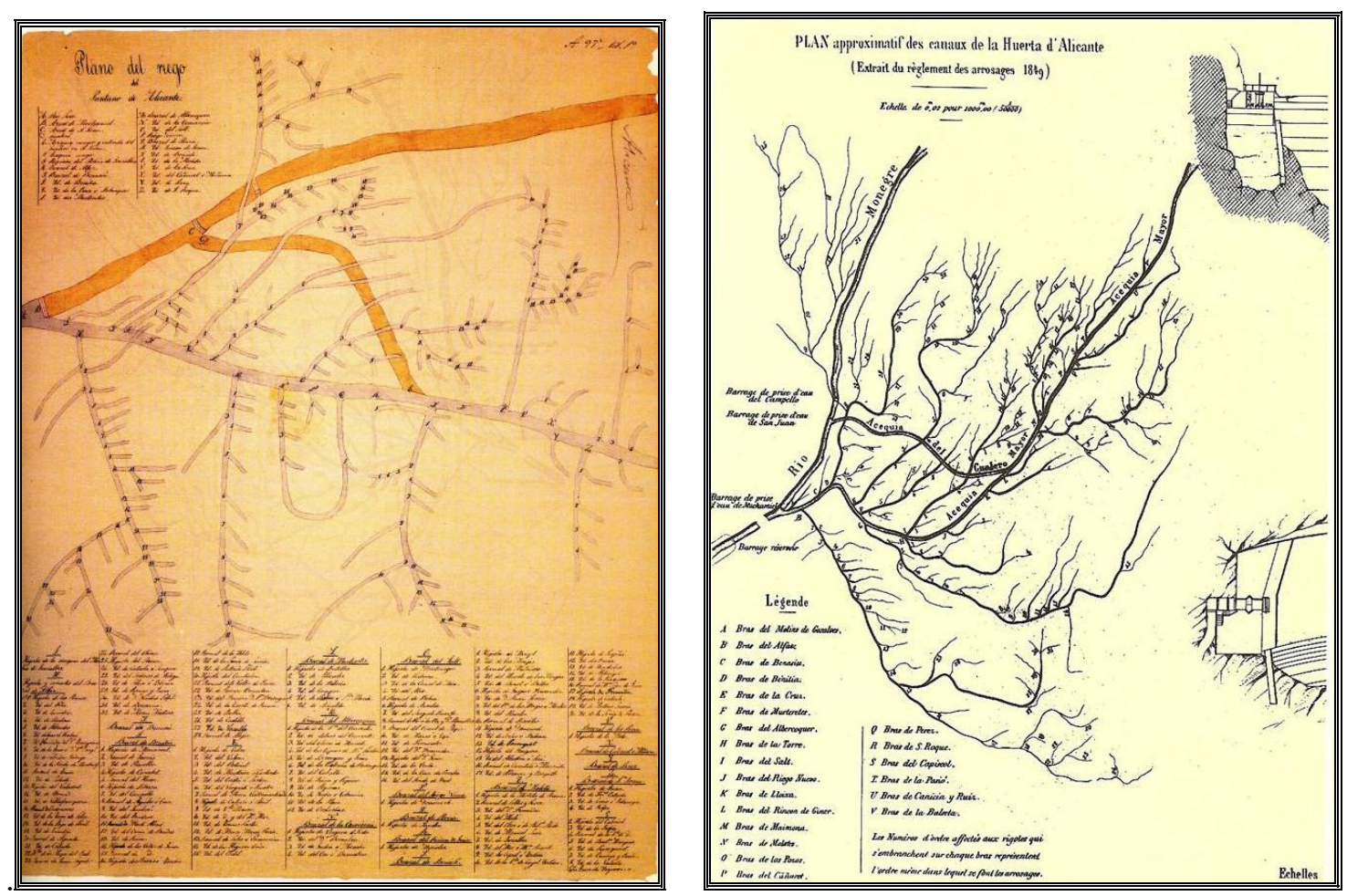

Fig. 2. Esquema del sistema de distribución del riego en la Huerta de Alicante según Roca de Togores (izquierda) y Aymard (derecha)

\section{Buscando soluciones: construcción del pantano de Tibi, reordenación del riego huertano y aparición de nuevos tipos de agua}

Se ha indicado que desde los primeros establecimientos medievales hasta bien entrado el siglo XVI se generalizaron en la huerta alicantina las prácticas monopolísticas de los principales dueños del agua quienes, mostrando un escaso interés por la explotación de sus propiedades agrarias, se dedicaron a especular a su antojo con los caudales de riego a los que, aparte de emplear en múltiples operaciones financieras, llegaron a poner precios abusivos ante la gran demanda de agua de riego. Pese a que diferentes sentencias y disposiciones regias declararon ilegales tales prácticas, el problema no se solucionó ${ }^{4}$. Hay referencias documentales que denuncian una reducción de la superficie cultivable de la huerta alicantina en casi dos tercios, alegando que muchos de sus labradores preferían dejar yermos sus campos antes que hacer frente a los arbitrarios precios del agua; no obstante estas afirmaciones no son verificables al carecer los archivos de las fuentes que nos permitirían comprobar tal extremo. Tampoco cabe perder de vista el rigor de las oscilaciones climáticas, por supuesto, las disputas cada vez más violentas que comenzaban a surgir con los vecinos de la cuenca alta del río Montnegre, quienes levantaban represas para desviar su curso y regar sus campos. Estas circunstancias son, fundamentalmente, las que decidieron al común de la ciudad a plantearse la construcción de un embalse con el que mitigar el creciente déficit hídrico.

\footnotetext{
${ }^{4}$ Archivo Municipal de Alicante (AMA), armario 5, libro 57, fol. 240.
} 
No es este lugar para extenderme en el relato de las peripecias de la empresa por lo que únicamente señalaré que las obras se desarrollaron entre 1579 y $1594^{5}$, período de tiempo en el que Alicante y su Huerta padecieron el embate de la sequía aunque, a poco de la conclusión de las obras y, más tarde, en los primeros días del mes de septiembre de 1597, hubo imponentes chubascos que, engrosando sobremanera los exiguos caudales del Montenegre, provocaron la inundación de la huerta y de parte de la villa de Mutxamel según se recoge en el Llibre de la confraria de Nostra Senyora de Loreto de Mutxamet. A lo largo de los siglos modernos se reproducirían este tipo de acontecimientos.

La presa de Tibi permitió asegurar el riego en la huerta alicantina, ampliar la superficie cultivable, atenuar el monopolio de los titulares de antiguas donaciones de agua y, sobre todo, perfeccionar un complejo sistema de reparto y distribución del agua, controlado por el municipio alicantino, de enorme trascendencia jurídico-económica. Asimismo, la construcción del pantano supuso duplicar, al menos teóricamente, la cantidad de agua disponible para el riego dividiéndose ésta en dos categorías. La asimilada al fluir natural del río recibió el nombre de agua vieja, se componía de 336 fils de hora y media de duración, estaba separada de la tierra y procedía de antiguas donaciones efectuadas en época medieval. El agua vieja constituía una propiedad por sí misma, pudiendo sus titulares venderla o comprarla independientemente de la tierra aunque únicamente a quienes poseyeran agua del nuevo riego del pantano.

El agua embalsada pasó a ser conocida como nueva y también se dividió en 336 fils, quedando adscrita a la tierra y distribuyéndose entre los labradores a razón de un minuto por tahúlla de tierra poseída ${ }^{7}$. La administración, control y distribución del riego -regido este último por un escrupuloso cómputo horario- fueron encomendados a la ciudad de Alicante que designó para ello a un funcionario municipal denominado sobrecequier. La ciudad mantendría estas competencias hasta 1740 en que, tanto el pantano como su sistema de riegos, pasaron a depender del Real Patrimonio por expreso deseo de Felipe V.

El detallado Memorial que reguló el nuevo estatus para riego y regantes, redactado y llevado a la práctica por el gobernador de los territorios meridionales del viejo reino valenciano a instancias de Felipe $\mathrm{II}^{8}$, pretendió, de un lado, establecer la inseparabilidad de agua y tierra para los beneficiarios del nuevo riego y, de otro, mantener los derechos adquiridos. Ello generó un doble juego de intereses entre los sucesores de los antiguos poseedores del agua donada por Alfonso X y los propietarios de tierras en la Huerta, con cuyo dinero y para su beneficio se había construido el pantano.

No obstante, el pretendido aumento de disponibilidad hídrica no iba más allá de una mera aspiración teórica. Testimonios contemporáneos dejan bien claro que el agua procedente del pantano o nueva no era continua, "porque passan a vezes años que no la hay, y aunque la baya no se saca sino quando lo insta la necesidads. ${ }^{9}$. Pese a que ello era cierto, conviene una matización: la consecuencia inmediata de la construcción del pantano de Tibi fue la inmediata y brusca reducción del precio del agua vieja. Por ello, los titulares de agua nueva, cuyo uso fue gratuito hasta 1622, prefirieron reservar ésta para los momentos de máxima escasez en los que, como

\footnotetext{
${ }^{5}$ El cierre efectivo tuvo lugar el 13 de octubre de 1593, embalsándose más de cuarenta palmos de agua en tres días - prueba de que hubo copiosas lluvias, pero la supervisión final no se produjo hasta comienzos de 1594 (Alberola, 1994).

${ }^{6}$ Cito por la edición y estudio de este libro llevados a cabo por Assumpció Brotons y Susana Llorens (2007).

7 AMA, armario 2, libro 1, fol. 100. La tahúlla en la Huerta de Alicante equivale a 0,1112 Ha.

8 AMA, armario 2, libro 1, ff. 71-74v.

${ }_{9}^{9}$ Real Academia de la Historia, A-617, I-43, fol. 2.
} 
es obvio, se disparaba el precio de la otra ${ }^{10}$. En cualquier caso, la posición preeminente de los titulares de agua vieja contribuyó a acentuar la rivalidad entre unos y otros pues los antiguos la disfrutaban no sólo en función de la extensión de sus tierras, sino merced a los diferentes negocios realizados desde el siglo XIII. De este modo quedaban acumuladas muchas horas de riego en muy pocas manos que, además, no poseían tierras. La realidad era que los propietarios de agua vieja actuaban como auténticos árbitros del riego huertano, puesto que el minuto de agua nueva concedido por tahúlla no solía ser suficiente (Altamira, 1896). Años más adelante las cosas se complicarían cuando, como he indicado, el agua nueva perdió en 1622 su carácter gratuito como consecuencia de la necesidad de hacer frente a los gastos derivados de la conservación del pantano, azudes y acequias, hasta ese momento soportados únicamente por el municipio alicantino ${ }^{11}$. Ciertamente el valor intrínseco del agua de riego adquirió valores excepcionales; tanto es así que para sufragar las obras de reconstrucción del pantano destruido en junio de 1697 por un sabotaje auspiciado por los titulares del agua vieja- se subastaran 16 hilos extra con las mismas características que ésta; hilos que fueron adquiridos por los más poderosos propietarios de la Huerta (Alberola, 1990). Rafael Altamira haría notar siglos después que las ventas del agua vieja, por un lado, y de los sobrantes de la nueva, por otro, fueron las que propiciaron el nacimiento del mercado de agua de la huerta alicantina (Altamira, 1905), institución singular regulada en su funcionamiento de manera consuetudinaria, hoy en día lamentablemente desaparecida.

Junto con el pantano de Tibi, los azudes de Mutxamel, Sant Joan y El Campello son testigos mudos -y muy deteriorados en la actualidad- de esa cultura de la necesidad hídrica y componen un sistema hidráulico que se reveló enormemente eficaz en la época moderna. A ellos se podrían añadir los molinos levantados en las riberas del Montnegre e, incluso, las conocidas como presas antiquísimas localizadas entre el pantano y el azud de Mutxamel. De más que probable origen medieval, la documentación de que disponemos sitúa la construcción -o mejora- de este azud en el último tercio del siglo XVI. El de Sant Joan data de las postrimerías del siglo XVI, aunque los primeros intentos se remontan a 1578; mientras que el proyecto para levantar el de El Campello está fechado en 1811 (Alberola, 1994). Todos ellos desempeñaron con eficacia la función de regular y dirigir los caudales del río hacia las diferentes acequias, brazales e hijuelas que surcaban la vieja huerta alicantina. Asimismo todos ellos sufrieron reiteradas destrucciones como consecuencia de los excesos hidrometeorológicos otoñales y las subsiguientes avenidas e inundaciones que dejaron hondas secuelas en la Huerta y sus poblaciones. Un reciente y espléndidamente documentado trabajo de Ágata Marquiegui recoge con precisión y abundante iconografía los vestigios de lo que cabe considerar, pese a las reticencias de ciertos políticos, parte de un auténtico patrimonio hidráulico alicantino (Marquiegui, 2013, II).

\section{Vaivenes climáticos y religiosos: sequía, inundaciones y rogativas en la Huerta de Alicante.}

\subsection{La Pequeña Edad del Hielo}

Los siglos modernos vienen a coincidir con la etapa climática conocida como Pequeña Edad del Hielo (PEH) (Alberola, 2014). Caracterizada por un descenso de las temperaturas medias de entre $1^{\circ}-2^{\circ} \mathrm{C}$, un incremento de las precipitaciones y una gran variabilidad; en la península Ibérica se padecieron igualmente largos períodos de extrema escasez hídrica interrumpidos, en otoño y primavera, por episodios de fuertes aguaceros de alta intensidad

10 AMA, armario 5, libro 57, ff. 241v-242.

11 AMA. armario 5, libro 57, fol. 242; RAH, A-617, I-43, fol. 2; AMA, armario 2, libro 2, ff. 419v-423v. 
horaria seguidos de riadas e inundaciones de consecuencias catastróficas. En la fachada mediterránea, la persistencia de la sequía junto con el notable incremento de la actividad tormentosa produjo un deterioro de las condiciones medioambientales que los contemporáneos percibieron con toda su crudeza. Al respecto se pueden distinguir tres fases u oscilaciones: 1570-1630, 1760-1800 y 1830-1870. La primera y la última fueron similares en intensidad, destacando el aumento en la frecuencia de las precipitaciones con efectos catastróficos y un ostensible descenso de las sequías. Durante el último cuarto del XVIII tuvo lugar una pulsación peculiar, conocida como oscilación Maldà, en la que sequía y grandes precipitaciones coincidieron en el tiempo (Barriendos, 2000, 2009). Por su parte, los picos de sequía frecuente o severa (alta frecuencia) se localizaron en los decenios 1560, 1620, 1750 y 1820; mientras que los correspondientes a secas moderadas o de baja frecuencia tuvieron lugar en 1700-1710, 1760-1770 y 1840-1860.

Estudios dendrocronológicos que han reconstruido la pluviometría de la actual provincia de Alicante durante el período 1550-1920, ponen de relieve su gran variabilidad hasta mediados del siglo XVII; sobre todo en los meses estivales que son en los que se localizan las mayores crisis secas (Creus y Saz, 2005). Para el conjunto del Levante peninsular aprecian tres fases de gran sequía en los períodos cálidos anuales; esto es entre los meses de abril y septiembre. La primera ocuparía la primera mitad y las décadas de los setenta y ochenta del siglo XVII, aunque intercalándose períodos lluviosos en 1650-1670 y 1688; la segunda se extendería durante los años que median entre 1760 y 1789 -con un pico lluvioso en 1739. Por último, desde fines del XVIII hasta comienzos del XX se alternan intervalos secos y húmedos de duración más reducida; no percibiéndose anomalías tan prolongadas como en los siglos XVII y XVIII. Las grandes secas convivieron con episodios hidrometeorológicos de rango extraordinario tardo estivales que provocaron, por ejemplo y durante el último tercio del siglo XVI, el desbordamiento del Turia e inundaciones en Valencia en los años 1577, 1581 y 1589, así como riadas en Alicante y su huerta en $1552^{12}, 1590^{13}$ y $1597^{14}$. El hecho de que el núcleo urbano alicantino carezca de curso fluvial que lo cruce -ramblas y barrancos aparte- hace que no abunden -salvo excepción- las noticias de riadas e inundaciones en él, recogiendo las fuentes documentales fundamentalmente las que afectaron al curso bajo del Montnegre, a la huerta y a sus poblaciones.

\subsection{Rogativas pro pluvia y pro serenitate}

Los años más secos y con menor precipitación en el Levante peninsular se localizan en la primera mitad del siglo XVII -1605, 1608, 1615-, destacando la especial dureza del decenio 1601-1610. Este extremo queda confirmado por la frecuencia en la celebración de rogativas pro pluvia y procesiones generales por agua llevadas a cabo tanto en la ciudad de Valencia como en la de Alicante y poblaciones de su huerta. Mossen Joan Porcar refiere las celebradas en la capital del reino durante 1608, 1609, 1612, 1613 y 1616 que convivieron con un par de avenidas del Turia en el verano de 1610 y en la primavera de 1611 (Porcar, 1585-1621, I,). Para Alicante y su huerta resulta imprescindible, la consulta del Llibre de la confraria de Nostra Senyora de Loreto, pues el archivo municipal alicantino tiene notorias carencias documentales en este período al igual que el de la antigua colegiata de San

\footnotetext{
12 De esta fecha data una de las pocas noticias referidas a estragos ocasionados en el casco urbano alicantino por las impetuosas corrientes que, tras un episodio de grandes lluvias, descendieron por las laderas del monte Bencantil. Parte del archivo municipal, temporalmente trasladado a la Lonja, fue destruido por la avalancha (Viravens, 1876).

13 AMA, armario 1, libro. 14, ff. 178-178v.

${ }^{14}$ Llibre de la confraria de Nostra Senyora de Loreto, p. 186.
} 
Nicolás; sobre todo por lo que hace al siglo XVI. En el Llibre se anotan, en ocasiones con gran detalle, las rogativas pro pluvia y procesiones penitenciales organizadas en los años 1625, 1627, 1628, 1629, 1631, 1632, 1634, 1635, 1636, 1638, 1657, 1669, 1680, 1686 у 1689. El empleo de expresiones como espantosa sequia, gran necesitat d'aigua per als camps o gran esterilitat es constante para justificar la puesta en marcha del protocolo que conducía a la celebración de unas ceremonias, en ocasiones espectaculares, en las que participaba todo el pueblo, con sus autoridades civiles y eclesiásticas a la cabeza y en las que no faltaron los incidentes por cuestiones de preeminencia institucional. Las rogativas por lluvia y, en su caso, las procesiones penitenciales iniciaban su marcha en la iglesia parroquial de Mutxamel desde donde, portando la imagen de la virgen de Loreto, se dirigían hacia el monasterio de la Santa Faz. Tras la celebración de misas y prédica de sermón retornaban al punto de partida. En ocasiones se ampliaba el recorrido a la práctica totalidad de la huerta y, en casos extremos, la rogativa llegaba hasta la ciudad de Alicante, pernoctando la virgen de Loreto y la Santa Faz en la colegiata de San Nicolás durante unos días. Lo habitual es que estas ceremonias se celebraran a finales del invierno y en puertas de la primavera

Dadas las circunstancias climáticas no resulta extraño que, a comienzos de la década de los treinta de esta centuria, se decidiera proseguir las obras de reconstrucción del azud de Sant Joan, arrasado por una avenida en 1590. No hubo mucha suerte pues, reparado entre los años 1631 y 1632, una gran tromba de agua seguida de una furiosa avenida volvió destrozar la presa en 1635 tal y como describe muy gráficamente el deán Bendicho y ratifica el Llibre de la Confraria. Previamente, en 1612 y 1617, hubo otros episodios similares que provocaron la inundación de Mutxamel y graves destrozos en el convento de la Santa Faz. El acontecido en 1617 dejó su impronta en toda la fachada oriental de la península Ibérica entre los últimos días de octubre y los primeros de noviembre. Conocido como l'any del diluvi, el carácter torrencial y destructivo de las lluvias ocasionó grandes estragos y generó abundante y detallada documentación referida a las calamidades sufridas en muchas poblaciones valencianas, catalanas y aragonesas (Barriendos, 2002; Pérez Samper, 2009).

En las décadas finales del siglo XVII la sequía fue persistente en tierras valencianas. Así lo acreditan las innumerables noticias proporcionadas por cronistas y dietaristas referidas, fundamentalmente, a la celebración en la ciudad de Valencia de muy diferentes rituales. Abundaron las oraciones por agua, rogativas, exposiciones del Santísimo y de reliquias de santos protectores junto con procesiones generales y de penitencia, observándose una estacionalidad similar en sus celebraciones -entre febrero y mayo- y una frecuencia de varias veces al mes. Tras producirse alguna precipitación, las ceremonias trocaban de inmediato su carácter pro pluvia en pro serenitate acompañándose de misas de acción de gracias y solemnes Te Deums. En las poblaciones de la huerta alicantina se repiten estas mismas circunstancias, pese a que la serie de que disponemos no está completa. No obstante hay constancia de la gran rogativa que se organizó el día 11 de marzo de 1657 después de haberse llevado a cabo las siete misas de gozos por agua preceptivas en la iglesia de Mutxamel. Una gran muchedumbre se desplazó hasta el convento de la Santa Faz portando cirios y antorchas, cargados con crucifijos y vestidos de penitencial. Tras escuchar una misa cantada seguida del correspondiente sermón, la comitiva inició el retorno, pasando por Sant Joan. Al llegar a Mutxamel se produjo «una gran mudança de temps, i plogué de alli en avant en gran abundància $i$ es cullgué raonablemente lo que no se esperava» ${ }^{15}$. A finales de mayo de 1669 y comienzos de febrero de 1680, ante lo terrible que estaba resultando la sequía, las rogativas tuvieron por destino la ciudad de Alicante. En ambas ocasiones los curas advirtieron a sus feligreses que si no llovía desde hacía dos años era por los pecados cometidos. En el primer caso se produjeron las ansiadas lluvias durante tres meses, de manera alterna, «ço es que ploia bui o nou dies de una, $i$ uns quants dies sense ploure, $i$ després tornavan. Menos suerte hubo en la segunda ocasión, a pesar

15 Llibre de la confraria...; p. 193. 
de que en su regreso desde Alicante la procesión hubo de acelerar la marcha ante la amenaza que suponía un cielo absolutamente nublado. Pero nada sucedió, pues «tot lo remei del aygua segons mostrava el temps es desván en un instantı. Para el rector de la parroquial de Mutxamel no había duda de que ello fue «senyal manifest de que nostros pecats eren grans». Sin embargo, el 4 de abril -mes lluvioso por excelencia- comenzó a llover y no cesó durante tres noches. El cura anotó en el Llibre de la Confraria la razón: «la infinita bondat de Nostre Senyor Deu Jesuchrist i la intercesió poderosa de Nostra Senyora».

\subsection{Extremismo hidrometeorológico, catástrofe y destrucción: sobreviviendo pese a todo.}

Las secas de comienzos de siglo XVIII fueron muy perjudiciales y estuvieron precedidas o convivieron con años de intenso frío y con los terribles efectos de la guerra de Sucesión. Durante los años veinte y treinta la sequía castigó con dureza las tierras valencianas, mientras que la de mediados de la centuria se prolongó hasta los años sesenta tal y como quedó reflejado a la perfección en las relaciones epistolares de algunos ilustrados (Alberola, 2010a). La correspondencia del humanista Manuel Martí, deán de la colegial de San Nicolás de Alicante, con Gregorio Mayans proporciona jugosa información sobre los «calores tartáreos» y «rigores caniculares» que decía padecer el deán, y la imposibilidad de combatirlos con eficacia, durante los terribles estíos de esos años; años en los que la huerta alicantina, como el resto del Levante peninsular, se agostaba como consecuencia de la sequía y de la rotura del pantano de Tibi. La situación adquirió tal gravedad que las rogativas pro pluvia, que desde comienzos de la década de los veinte venían celebrándose en secreto, pasaron a ser públicas a partir del año 1725, decidiéndose los responsables políticos y religiosos de la urbe alicantina a traer en procesión la reliquia de la Santa Faz (Alberola, 2010a).

La información referida a rogativas durante el siglo XVIII, a diferencia de los dos siglos anteriores, es abundante y prolija reflejando perfectamente la situación existente en el campo alicantino a lo largo de la centuria. Los vaivenes meteorológicos vienen a coincidir con las oscilaciones de las cosechas, las fases de crisis vividas en la ciudad y su huerta y la disponibilidad de agua para riego (Bueno, 2013). Éste último pasó a estar controlado por el Real Patrimonio tras la reconstrucción del pantano de Tibi en diciembre de 1738 y la promulgación de nuevas ordenanzas a cargo de José Fondesviela, intendente de Valencia. Los datos procedentes de acuerdos municipales y de celebración de rogativas denotan que durante la primera mitad del siglo XVIII apenas hubo acontecimientos hidrometeorológicos extraordinarios. La única referencia a una gran crecida del río Montnegre el día 12 de octubre de 1736 se halla en el Llibre de la Confraria. Sin embargo, a partir del ecuador de la centuria -sobre todo, en su último cuarto y coincidiendo con la presencia de la denominada anomalía u oscilación Maldà (1760-1800)- la inestabilidad atmosférica se adueñó del Mediterráneo español. En estos años, como ya se ha indicado, se produjo un insólito fenómeno: la sequía mantuvo su rigor en todo momento pero coexistió con violentos aguaceros otoñales. Las consecuencias, tanto de la extremada carencia hídrica como de su exceso, resultaron catastróficas. Abundante información de carácter oficial así como testimonios de quienes padecieron esos sucesos, recogen estos extremos y nos permiten componer los perfiles socioeconómicos de una realidad compleja y difícil (Bueno, 2013).

Especialmente duras resultaron las sequías en la huerta alicantina en los años sesenta, con solemnes rogativas que implicaron el traslado a la ciudad de Alicante de la reliquia de la santa Faz (Viravens, 1876). La situación se mantendría durante la década postrera del siglo 
y la primera del XIX aunque, eso sí, alterada brusca y catastróficamente de tanto en tanto como consecuencia de episodios hidrometeorológicos extremos que ocasionaron daños muy graves en los cultivos, infraestructuras hidráulicas y cascos urbanos de las poblaciones huertanas.

De las trágicas consecuencias dejadas por el tremendo temporal del otoño de 1783 en todo territorio valenciano sólo tenemos constancia para Alicante de las avenidas que, tras las intensas lluvias del mes de septiembre, destruyeron el puente que la unía a Xixona y que dejó aisladas ambas poblaciones durante seis años; los que se tardó en reparar la infraestructura (Alberola, 1999). La imponente riada de mediados de agosto de 1789 destruyó los azudes de Mutxamel y Sant Joan, inutilizó la acequia mayor de la huerta alicantina y arrasó las producciones agrícolas. Un minucioso informe del administrador del pantano refiere muy gráficamente cómo el primero de los azudes desapareció bajo el ímpetu de las aguas junto con su casamata de gobierno y el segundo tragante. El de Sant Joan resistió mejor, pero el reparo de sus daños ascendió a 50.000 reales. Dos años más tarde, la ciudad de Alicante sufriría los efectos de las intensas precipitaciones que se desencadenaron a comienzos de noviembre y que convirtieron las ramblas y barrancos sobre las que se asienta el callejero urbano en auténticas torrenteras de alto poder destructivo. Pocos días antes se habían llevado a cabo rogativas pro pluvia (Viravens, 1876; Jover, 1863).

Buena parte de la geografía valenciana, especialmente Castellón de la Plana, Alcoi y Valencia, soportó fuertes avenidas como consecuencia de la gran tempestad que descargó en la noche del 7 de septiembre de 1793. En la huerta de Alicante sus efectos resultaron demoledores. Ésta fue, junto con la de 1789, una de las riadas más destructivas del siglo pues, tras sobrepasar las aguas sobradamente la terraza del pantano de Tibi, se precipitaron con gran violencia hacia la huerta. Los caminos quedaron cortados, los molinos harineros dejaron de funcionar y los campos de cultivo que se extendían por las riberas del Montnegre, aguas abajo del pantano, perdieron todos los frutos. A comienzos de abril de 1794 una nueva riada destruyó el conocido como Molí Nou, próximo al arruinado azud de Mutxamel, ocasionó serios desperfectos en la acequia mayor y penetró con furia en los campos alicantinos. Paralelamente se iniciaba el proceso de reconstrucción de los azudes, empeño que no culminaría hasta comienzos del siglo siguiente (Alberola, 1999, 310-313).

Mientras tanto, y excepción hecha de estos períodos equinocciales, la sequía continuaría instalada en todo su rigor y los contemporáneos, constantes en sus rezos y rogativas en demanda de lluvia, tampoco cejarían en su empeño de buscar y aplicar todos los recursos técnicos -a su alcance o no- para hacerle frente. A sabiendas de que estaban condenados a padecer por siempre los excesos y carencias hídricas. En efecto, la maldición pervive a día de hoy.

\section{Agradecimientos}

Este trabajo ha sido elaborado en el marco del proyecto de investigación HAR2013-44972-P, incluido en el Programa Estatal de Fomento de la investigación científica y técnica de excelencia promovido por el MINECO (Gobierno de España).

\section{Referencias}

Alberola, Romá. A. (1984): Jurisdicción y propiedad de la tierra en Alicante, ss. XVII y XVIII, Alicante, Ayuntamiento de Alicante-Universidad de Alicante. 
Alberola Romá, A. (1990): Agricultores y monopolistas: el control del agua de riego en las comarcas meridionales del País Valenciano durante la edad moderna, en Pérez Picazo, $\mathrm{M}^{\mathrm{a}} \mathrm{T}$. y Lemeunier, G., Eds.: Agna y modo de producción, Barcelona, Crítica, pp. 188-211

Alberola Romá, A. (1994): El pantano de Tibi y el sistema de riegos en la Huerta de Alicante, Alicante, Instituto Juan Gil-Albert-Fundación Cultural CAM. $2^{\text {a }}$ edición, corregida y aumentada.

Alberola Romá, A. (1996): Tibi, una presa modélica de fines del Quinientos. La visión de cronistas, viajeros e ingenieros de los siglos XVII al XIX, en Alberola, A., Ed.: Cuatro siglos de técnica bidráulica en tierras alicantinas, Alicante, Instituto de Cultura Juan Gil-Albert, pp. 141-158.

Alberola Romá, A. (1999): Catástrofe, economía y acción política en la Valencia del siglo XVIII, Ed. Alfons el Magnànim, Valencia.

Alberola Romá, A. (2010a): «No puedo sujetar la pluma de puro frío, porque son extremados los yelos. El clima en la España de los reinados de Felipe $\mathrm{V}$ y Fernando VI a través de la correspondencia de algunos ilustrados», Investigaciones Geográficas, 49: 65-88

Alberola Romá, A. (2010b): Quan la pluja no sap ploure. Sequeres i riuades al País Valencia en l'edadt moderna, València, Publicacions de la Universitat de València.

Alberola Romá, A. (2011): Miedo y religiosidad popular: el mundo rural valenciano frente al desastre meteorológico en la Edad Moderna. Apuntes para su estudio, en Marcos Martín, A., Ed.: Hacer historia desde Simancas. Homenaje a José Luis Rodríguez de Diego, Valladolid, Junta de Castilla y León, pp. 11-30.

Alberola Romá, A. (2014): Los cambios climáticos. La Pequeña Edad del Hielo en España, Cátedra, Madrid.

Altamira y Crevea, R. (1896): Mercado de agua para riego en la huerta de Alicante y otras localidades próximas, en Costa, J.: Derecho consuetudinario y economía popular en España, Zaragoza, 1981, vol. II.

Altamira y Crevea, R. (1905): Derecho consuetudinario y economía popular en la provincia de Alicante, Madrid, Imprenta del Asilo de huérfanos del S. C. de Jesús.

Altamira, R. (1895): La fiesta del agua, en Cuentos de Levante, Est. Tip. Noviciado, $\mathrm{n}^{\mathrm{o}}$ 16, Madrid; ver asimismo este relato corto en Cuentos de Levante y otros relatos breves, edición, introducción y notas de $\mathrm{M}^{\mathrm{a}}$ Ángeles Ayala, Alicante, Fundación Altamira, 1998.

Aymard, M. (1864): Irrigations du Midi de l'Espagne, París.

Barriendos, M. (2000): La climatología histórica en España. Primeros resultados y perspectivas de la investigación, en J. C. García Codrón, Coord.: La reconstrucción del clima de época preindustrial, Santander, Servicio de Publicaciones de la Universidad de Cantabria, pp. 17-56

Barriendos, M. (2002): Los riesgos climáticos a través de la Historia. Avances en el estudio de episodios atmosféricos extraordinarios, en Ayala-Carcedo, F. J. y Olcina Cantos, J., Coords.: Riesgos naturales, Barcelona, Ariel Ciencia, pp. 549-562.

Barriendos, M. y Llasat, C. (2009): El caso de la anomalía "Maldà" en la cuenca mediterránea occidental (1760-1800). Un ejemplo de fuerte variabilidad climática, en Alberola, A. y Olcina, J., Eds.: Desastre natural, vida cotidiana y religiosidad popular en la España moderna y contemporánea, Alicante, Publicaciones de la Universidad de Alicante, pp. 253-286

Bendicho, V. (1640): Chronica de la M. I. noble, y leal ciudad de Alicante, año 1640. Manuscrito conservado en el Archivo Municipal de Alicante. Hay transcripción y edición crítica a cargo de Cabanes Catalá, Mª L. (1991), Alicante, Ayuntamiento de Alicante, 4 vols 
Brotons Boix, A. y Llorens Ortuño, S. (2007): Estudi del Llibre de la confraria de Nostra Senyora de Loreto de Mutxamel, Alicante CAM.

Bueno Vergara, E. (2013): Un indicador climático para el alicante del siglo XVIII: los manifiestos del vino, en Alberola Romá, A., Coord.: Clima, naturaleza y desastre. España e Hispanoamérica durante la Edad Moderna, València, Publicacions de la Universitat de València, pp. 55-80.

Cavanilles, A. J. (1795-1797): Observaciones sobre la bistoria natural, geografía, agricultura, población y frutos del Reyno de V alencia, Madrid, Imprenta Real, 2 vols.

Conca, A. (1797): Descrizione odeporica della Spagna in cui spezialmente si da' notizia delle cose spettanti alle Belle Arti degne dell'atten₹ione del curioso viaggiatore; di don ---, socio delle Reali Accademie Fiorentina e de' Georgofili. Parma. Dalla Stamperia Reale, T. IV, p. 391.

Creus Novau, J. y Saz Sánchez, M. A. (2005): Las precipitaciones de la época cálida en el sur de la provincia de Alicante desde 1550 a 1915, Revista de Historia Moderna. Anales de la Universidad de Alicante, 23: 35-48

Gil Olcina, A. (1968): El regadío de Elche, en Estudios Geográficos, 112-113: 527-574.

Gil Olcina, A. (1993): La propiedad de aguas perennes en el sureste ibérico, Alicante, Universidad de Alicante.

Giménez, López, E. (1981): Alicante en el siglo XVIII. Economía de una ciudad portuaria del Antiguo Régimen, Valencia, Ed. Alfons el Magnànim.

Glick, Th. F. (1988): Regadío y sociedad en la Valencia Medieval, Valencia.

Jover, N. C. (1863): Reseña histórica de la ciudad de Alicante, Alicante, Imp. y Lit. de la V. de Juan J. Carratalá.

Le Roy Ladurie, E. (1991): Historia del clima desde el año 1000, México, Fondo de Cultura Económica.

López Gómez, A. (1951): Riegos y cultivos en la Huerta de Alicante. Evolución y estado de la cuestión, Estudios Geográficos, 41: 701-771.

Llauradó, A. (1884): Tratado de aguas y riegos, Madrid, Imp. de Moreno y Rojas, 2 vols.

Markham, C. (1867): Report on the Irrigation of Eastern Spain, London (hay traducción al catalán titulada El regadiu de l'Espanya de l'Est (1867), con Estudio Preliminar a cargo de Th. F. Glick, Valencia, Ed. Alfons el Magnànim, 1991).

Marquiegui Soloaga, A. (2013): El patrimonio bidráulico de la provincia de Alicante. Catálogo ilustrado de mil quinientas obras y actuaciones, Alicante, Diputación de Alicante.

Mateu Bellés, J. F. (1995): Cavanilles i l'ofici il.lustrat de viatjar, en Les Observacions de Cavanilles. Dos-cents anys després, València, Fundació Bancaixa, Llibre primer.

Pérez Samper, Ma A. (2009): Alimentación y desastres naturales, en Alberola, A. y Olcina, J., Eds.: Desastre natural, vida cotidiana y religiosidad popular en la España moderna y contemporánea, Alicante, Publicaciones de la Universidad de Alicante, pp. 131-208.

Porcar, P. J. (1585-1629): Coses evengudes en la ciutat y regne de València. Dietari (1585-1629); Edició a cura de Josep Lozano, València, Universitat de València, 2012, II vols.

Roca de Togores, J. (1849): Memoria sobre el estado de la agricultura en la provincia de Alicante (...), Madrid, Boletín Oficial del Ministerio de Comercio, Instrucción y Obras Públicas, tomo VI. 
Romero González, J. (1995): El Plan Nacional de Obras Hidráulicas. Precedentes y condicionantes, en Gil Olcina, A. y Morales Gil, A., Eds., Planificación hidráulica en España, Murcia, Fundación CAM.

Verdú, F. (1739): Discurso sobre el dominio, pertenencia, distribución y uso de las aguas que sirven al riego público de la buerta de esta ilustre ciudad de Alicante, Alicante.

Vergara y Paravecino, J. B. (1739): Manifiesto histórico-legal de las especies y adquisición del agua que fluye a la vega de Alicante por el río nombrado de Cavanes (...). Alicante.

Viravens Pastor, R. (1876): Crónica de la muy ilustre y siempre fiel ciudad de Alicante, Alicante, Imprenta de Carratalá y Gadea. 